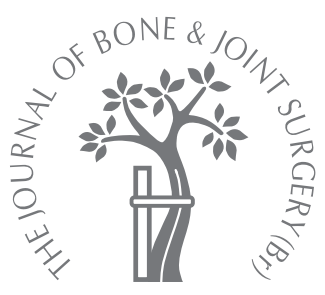

T. Sakai, K. Ohzono, T. Nishii, H. Miki, M. Takao, N. Sugano

From Osaka University Graduate School of Medicine, Suita, Japan

\section{A modular femoral neck and head system works well in cementless total hip replacement for patients with developmental dysplasia of the hip}

\begin{abstract}
We compared a modular neck system with a non-modular system in a cementless anatomical total hip replacement (THR). Each group consisted of $\mathbf{7 4}$ hips with developmental hip dysplasia. Both groups had the same cementless acetabular component and the same articulation, which consisted of a conventional polyethylene liner and a $28 \mathrm{~mm}$ alumina head. The mean follow-up was 14.5 years (13 to 15), at which point there were significant differences in the mean total Harris hip score (modular/non-modular: 98.6 (64 to $100) / 93.8(68$ to 100$))$, the mean range of abduction $\left(32^{\circ}\left(15^{\circ}\right.\right.$ to $\left.40^{\circ}\right) / 28\left(0^{\circ}\right.$ to $\left.\left.40^{\circ}\right)\right)$, use of a $10^{\circ}$ elevated liner $(31 \% / 100 \%)$, the incidence of osteolysis $(27 \% / 79.7 \%)$ and the incidence of equal leg lengths ( $\geq 6 \mathrm{~mm}, 92 \% / 61 \%)$. There was no disassociation or fracture of the modular neck.

The modular system reduces the need for an elevated liner, thereby reducing the incidence of osteolysis. It gives a better range of movement and allows the surgeon to make an accurate adjustment of leg length.
\end{abstract}

- T. Sakai, MD, PhD, Assistant Professor

M. Takao, MD, PhD, Assistant Professor

Department of Orthopaedic

Surgery

= T. Nishii, MD, PhD, Associate

Professor

N. Sugano, MD, $\mathrm{PhD}$,

Professor

Department of Orthopaedic

Medical Engineering

Osaka University Graduate

School of Medicine, 2-2,

Yamadaoka, 565-0871 Suita,

Japan.

= K. Ohzono, MD, PhD, Vice President

Department of Orthopaedic

Surgery

Kansai Rosai Hospital, 3-1-69,

Inabasou, 660-8511,

Amagasaki, Japan.

In. Miki, MD, PhD,

Orthopaedic Surgeon

Department of Orthopaedic

Surgery

Osaka National Hospital, 2-1-14,

Hoenzaka, Chuo-ku, 540-0006,

Osaka, Japan.

Correspondence should be sent

to $\mathrm{Dr}$ T. Sakai; e-mail:

tsakai-osk@umin.ac.jp

(C)2010 British Editorial Society

of Bone and Joint Surgery

doi:10.1302/0301-620X.92B6

$23001 \$ 2.00$

$J$ Bone Joint Surg $[\mathrm{Br}]$ 2010;92-B:770-6.

Received 26 June 2009;

Accepted after revision 27

January 2010
A hip system that incorporates a modular head and neck has several theoretical advantages in that leg length, femoral anteversion and femoral offset can all be adjusted. ${ }^{1,2}$ Its ability to control femoral anteversion and offset has been shown by comparing pre- and postoperative CT scans. ${ }^{3}$

The additional junction between the neck and the stem can, however, cause problems, including fretting wear, ${ }^{4}$ corrosion, ${ }^{5}$ fracture and disassociation. ${ }^{6}$ These have been described at the head-neck interfaces. ${ }^{7-11}$ The long-term advantages and disadvantages of the modular neck system are not well documented. We therefore investigated whether a modular neck system would give better long-term clinical and radiological results than a non-modular system, and whether there would be complications related to the modular neck.

\section{Patients and Methods}

We retrospectively studied 67 patients (83 hips) with a modular system (modular group) and 66 patients ( 80 hips) with a non-modular system (non-modular group) who had undergone a cementless total hip replacement (THR) for osteoarthritis secondary to developmental dysplasia between January 1994 and July 1996. The choice of components was made pre-operatively, taking age, gender and the classification system of Crowe, Mani and
Ranawat ${ }^{12}$ into account. Consecutive patients were divided into these two cohorts with the matching of age, gender and Crowe classification. All patients had been operated on by a team of two hip surgeons (KO and NS).

In the modular group one patient (one hip) died within ten years from an unrelated disease, and six (eight hips) were lost to followup. In the non-modular group six patients (six hips) were lost to follow-up. Therefore, both study groups consisted of 74 hips. The mean follow-up was 14.5 years (13 to 15 ). There were 67 women and seven men in the modular group, and 69 women and five men in the nonmodular group. There were no significant differences in the physical characteristics of the two groups (Table I). There were 35 Crowe I ( $\leq 50 \%$ subluxation), 30 Crowe II $(50 \%$ to $75 \%$ subluxation) and nine Crowe III hips ( $75 \%$ to $100 \%$ subluxation) in each group. Patients with Crowe IV hips were not included in the study, which received ethical approval.

Each operation was carried out using a posterolateral approach without trochanteric osteotomy. A total capsulectomy was performed to increase the range of movement and to allow an increase in leg length.

On the femoral side, cementless femoral components were used in each group. In the modular group we used a custom-designed femoral component and a modular neck system (Fig. 1) 
Table I. Pre-operative characteristics of the two groups

\begin{tabular}{|c|c|c|c|}
\hline Parameters & Modular (74 hips) & Non-modular (74 hips) & p-value $^{\dagger}$ \\
\hline Mean age in years (range) & $52.9(40$ to 73$)$ & 54.7 (36 to 72$)$ & - \\
\hline \multicolumn{4}{|l|}{ Gender } \\
\hline Male:female & $7: 67$ & $5: 69$ & - \\
\hline Mean height (cm) (range) & $152.6(130$ to 175$)$ & $152.5(127$ to 170$)$ & n.s. ${ }^{\ddagger}$ \\
\hline Mean weight (kg) (range) & 54.7 (38 to 68$)$ & 55.8 (39 to 88$)$ & n.s. ${ }^{\ddagger}$ \\
\hline Mean body mass index (range) & 23.5 (17.3 to 30.6$)$ & $24.0(18.0$ to 36.1$)$ & n.s. ${ }^{\ddagger}$ \\
\hline Crowe's classification (I/II/III, hips) ${ }^{*}$ & $35 / 30 / 9$ & $35 / 30 / 9$ & n.s. ${ }^{\S}$ \\
\hline \multicolumn{4}{|l|}{ Mean pre-operative Harris hip score } \\
\hline Range of movement (range) & $3.77(0.6$ to 5$)$ & $3.85(0.75$ to 4.88$)$ & n.s. ${ }^{\ddagger}$ \\
\hline Total (range) & $44.6 \quad$ (18.4 to 70.5$)$ & $46.6 \quad(16.1$ to 65.7$)$ & n.s. ${ }^{\ddagger}$ \\
\hline \multicolumn{4}{|l|}{ Mean range of movement } \\
\hline Flexion $\left({ }^{\circ}\right)$ & $71(10$ to 110$)$ & $72 \quad(15$ to 120$)$ & n.s. ${ }^{\ddagger}$ \\
\hline Abduction $\left({ }^{\circ}\right)$ & $13(0$ to 30$)$ & $14.9(0$ to 35$)$ & n.s. ${ }^{\ddagger}$ \\
\hline \multicolumn{4}{|c|}{ * group $1,<50 \%$ subluxation; group $2,50 \%$ to $75 \%$ subluxation; group III, $75 \%$ to $100 \%$ subluxation } \\
\hline \multicolumn{4}{|c|}{ a p-value of $<0.05$ indicated statistical significance; N.S. not significant } \\
\hline \multicolumn{4}{|c|}{ ‡ Mann-Whitney U test } \\
\hline$\S$ chi-squared test & & & \\
\hline
\end{tabular}

made from titanium alloy (Ti-6A1-4V) (Cremascoli, Milan, Italy) with a $28 \mathrm{~mm}$ Biolox alumina femoral head (CeramTec, Plochingen, Germany). ${ }^{13}$ The surface of the stem was grit-blasted for biological fixation. After inserting the femoral component, the modular neck and head were used to adjust offset and anteversion. Offset was altered by using the modular necks in 65 hips $(87.8 \%)$ : a neutral short/long neck was used in 63 hips, a varus short neck in one, and a lateralised short neck in one. We aimed for between $15^{\circ}$ and $30^{\circ}$ of anteversion of the femoral neck. Anteverted/ retroverted necks were used in nine hips (12.2\%) (Fig. 2). In the non-modular group we used an anatomical metal cancellous femoral component made from a cobaltchrome-molybdenum alloy (ESKA, Lubeck, Germany) with the same $28 \mathrm{~mm}$ Biolox alumina femoral head. ${ }^{14,15}$ The surface of this stem has a structure like that of cancellous bone. The modular head system in both groups consisted of three increments: short $(-3.5 \mathrm{~mm})$, medium $(0 \mathrm{~mm})$, and large $(+3.5 \mathrm{~mm})$. There was no significant difference in the distribution of the ceramic head increments (Table II). The headneck ratio was $2.0(28 \mathrm{~mm} / 13.8 \mathrm{~mm})$ in each group.

On the acetabular side we used the same cementless metal cancellous acetabular component (ESKA) with a gamma-sterilised conventional polyethylene liner (ESKA) in every case. ${ }^{14,15}$ There was no significant difference in the distribution of the outer diameter of the acetabular components between the two groups (Table II). Morsellised autogenous bone retrieved after reaming the acetabulum was used to augment the uncovered superolateral part of the acetabular components and to fill cysts in the acetabulum.

A neutral or a $10^{\circ}$ elevated polyethylene liner was chosen based on the stability of the hip after trial reduction.
All patients received prophylactic intravenous antibiotics with $2 \mathrm{~g}$ of second-generation cephalosporins on induction and $2 \mathrm{~g}$ every 12 hours for 72 hours. Anticoagulants were not given. Elastic stockings were used for the first two postoperative weeks. Partial weight-bearing was allowed after one week, and full weight-bearing after three weeks, provided there were no complications.

Clinical and radiological data were evaluated by two independent authors (TS and NS) who were blinded to the results. The clinical results were evaluated pre-operatively and at the latest follow-up using the Harris hip score $(\mathrm{HHS})^{16}$ and the range of movement of the hip.

Anteroposterior (AP) and true lateral radiographs were taken pre-operatively and at each follow-up. The location of the centre of the hip was taken to be the centre of the femoral head on the immediate post-operative AP radiograph. The vertical distance from the teardrop and the lateral distance from the vertical line through the symphysis pubis ${ }^{17}$ were computed (ImageJ 1.42q, National Institutes of Health, Bethesda, Maryland). Migration of the femoral component was determined by measuring the vertical distance from the shoulder of the stem to the midpoint of the lesser trochanter. Angulation of the stem was measured between the axis of the stem and that of the proximal femur. Vertical migration of $>4 \mathrm{~mm}$ or a change of $>2^{\circ}$ in the valgus/varus angle were taken to indicate loosening. ${ }^{18}$ Loosening of the acetabular component was defined as migration of $>2 \mathrm{~mm}$ or a change of $>5^{\circ}$ in the abduction angle. ${ }^{18}$ We also noted the presence or absence of femoral and acetabular osteolysis. Osteolysis was defined as an area of endosteal, intracortical or cancellous loss of bone with scalloping, or loss of bone other than that from disuse 


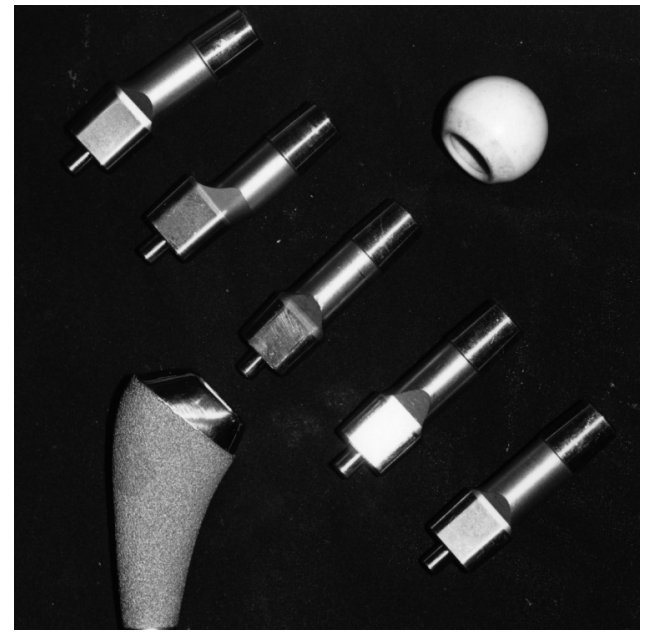

Fig. 1a

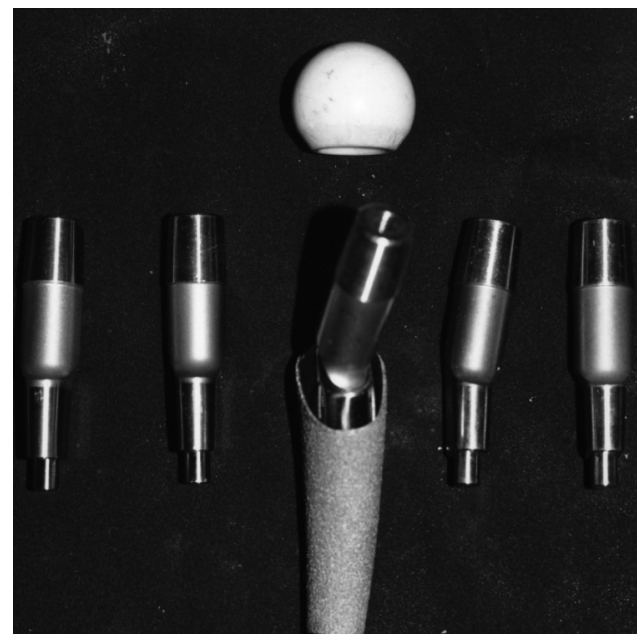

Fig. 1b

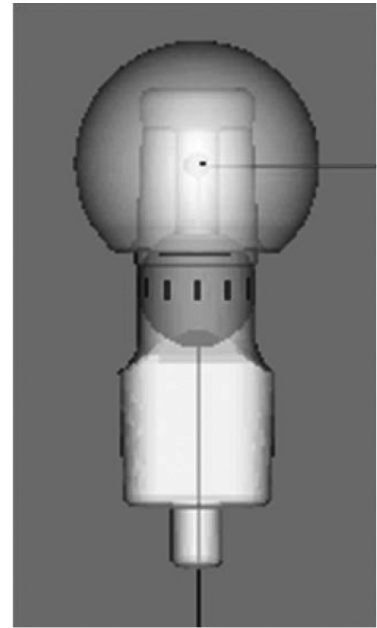

Fig. 1c

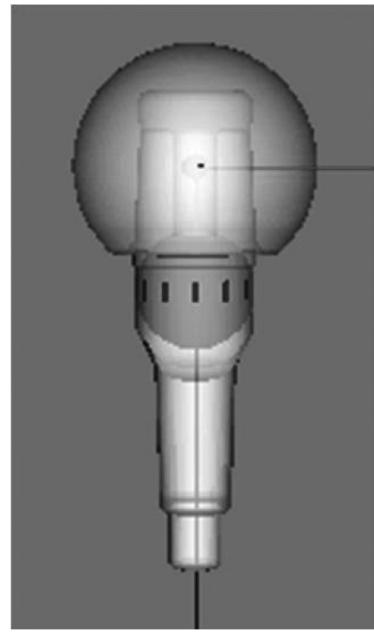

Fig. 1d

Images of a) Anteroposterior (AP) view of the modular femoral neck system, b) the lateral view and c) AP and d) lateral views of the modular neck showing that the head-neck ratio is $2.0(28 \mathrm{~mm} / 13.8 \mathrm{~mm})$.

osteopenia. ${ }^{19}$ Penetration of the head into the polyethylene liner was not measured because the entire outline of the ceramic head could not be seen in the metal acetabular shell with conventional plain radiographs $(70 \mathrm{kVp}, 12.5 \mathrm{mAs}) . \mathrm{In}$ cases of osteolysis, radiological examination with highvoltage radiographs $(120 \mathrm{kVp}, 20 \mathrm{mAs})$ was carried out in order to measure the migration of the hip centre and the amount of polyethylene wear. Differences in post-operative leg-length were determined radiologically by measuring from the acetabular teardrop to the lesser trochanter on each side. ${ }^{20}$ Differences of $>6 \mathrm{~mm}$ were considered significant. ${ }^{21}$ Statistical analysis. Analysis of outcome between the two groups was performed using the non-parametric MannWhitney $U$ test, chi-squared test and Fisher's exact probability test. A p-value of $<0.05$ was considered statistically significant.

\section{Results}

There were significant differences in the mean total HHS at follow-up (modular group/non-modular group: 98.6 (64 to 100$) / 93.9$ (68 to 100$), \mathrm{p}<0.0001))$, mean range of abduction $\left(32^{\circ}\left(15^{\circ}\right.\right.$ to $\left.40^{\circ}\right) / 28^{\circ}\left(0^{\circ}\right.$ to $\left.\left.40^{\circ}\right), \mathrm{p}=0.002\right)$, incidence of femoral osteolysis (20 hips $(27 \%) / 57$ hips $(77 \%), p<0.0001)$, and the incidence of acetabular and femoral osteolysis (20 hips $(27 \%) / 59$ hips $(79.7 \%), p<$ 0.0001 ) at the latest follow-up (Table III). In the nonmodular group, two acetabular components needed revision because of aseptic loosening and varus migration. In the modular group, $10^{\circ}$ elevated liners were used in 23 hips (31\%) and neutral liners in 51 (69\%) (Fig. 3), whereas in the non-modular group $10^{\circ}$ elevated liners were used in all 74 hips $(100 \%)(\mathrm{p}<0.0001)$ (Table II). The elevated liners in the non-modular group were 


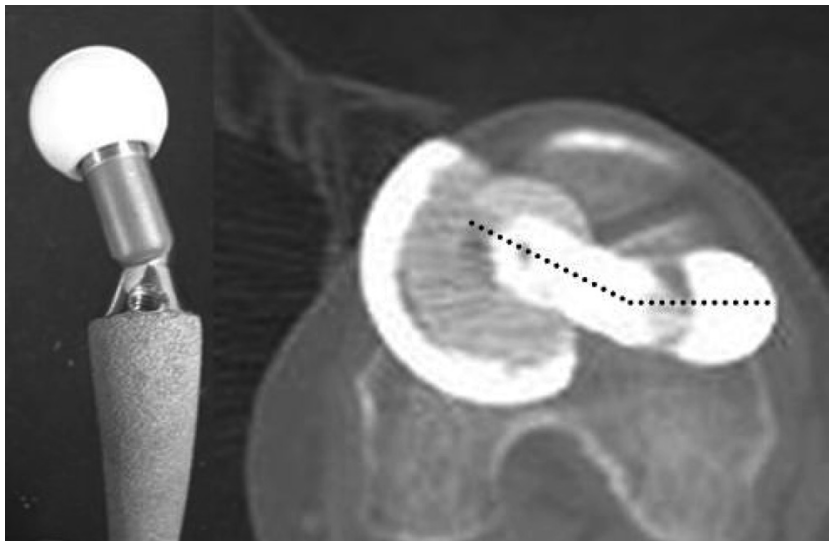

Fig. 2a

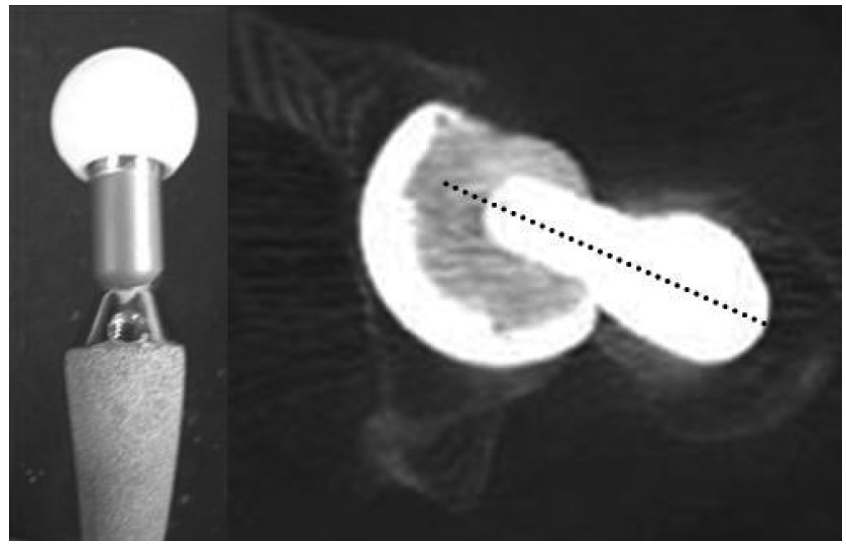

Fig. $2 b$

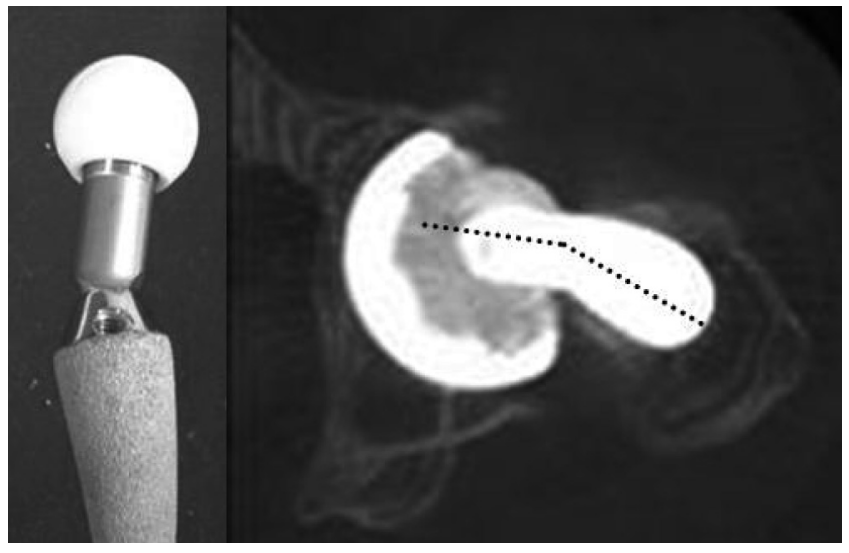

Fig. 2c

Post-operative modified CT scans showing a) the combination of the acetabular component with a $15^{\circ}$ anteverted short neck, b) a neutral short neck, and c) a $15^{\circ}$ retroverted short neck.

Table II. Operative characteristics of the two groups

\begin{tabular}{|c|c|c|c|}
\hline Parameters & Modular (74 hips) & Non-modular (74 hips) & p-value $^{*}$ \\
\hline \multicolumn{4}{|l|}{ Implant } \\
\hline Socket size (44 to $48 / 52$ to 56 , hips) & $59 / 15$ & $58 / 16$ & n.s. \\
\hline Ceramic head increment (S/M/L, hips) & $22 / 31 / 21$ & $24 / 37 / 13$ & n.s. \\
\hline Polyethylene insert (elevated/neutral, hips) & $23 / 51$ & $74 / 0$ & $<0.000^{1}$ \\
\hline \multicolumn{4}{|l|}{ Modular neck } \\
\hline Neutral S/L & $11 / 52$ & - & \\
\hline 15retro S/L & $1 / 7$ & - & \\
\hline 15antL & 1 & - & \\
\hline LateralisedS & 1 & - & \\
\hline VarusS & 1 & - & \\
\hline
\end{tabular}

* chi-squared test, $\mathrm{p}$-value $<0.05$ was considered statistically significant; n.s., not significant

† Fisher's exact probability test

associated with more osteolysis than the neutral liners in the modular group ( $\mathrm{p}<0.0001$, Table IV, Fig. 4). There were no significant differences in pre-operative HHS, range of movement, location of the hip centre, cup loosening, stem loosening or revision surgery at the latest follow-up. High-voltage radiation was used to examine 72 hips with osteolysis. There were 13 of these in the modular group and 59 in the non-modular group. They showed migration of the hip centre due to polyethylene wear in all hips (Fig. 4c). Radiological measurements of 
Table III. Post-operative characteristics between the two groups (n.s., not significant)

\begin{tabular}{|c|c|c|c|}
\hline Parameters & Modular (74 hips) & Non-modular (74 hips) & p value \\
\hline \multicolumn{4}{|l|}{ Harris hip score at the latest follow-up } \\
\hline Range of movement (range) & $4.75(3.38$ to 5$)$ & $4.61(0.05$ to 5$)$ & $0.05^{\dagger}$ \\
\hline Total (range) & $98.6 \quad(64$ to 100$)$ & $93.9(68$ to 100$)$ & $<0.0001^{\dagger}$ \\
\hline \multicolumn{4}{|l|}{ Range of motion } \\
\hline Flexion $\left(^{\circ}\right)$ (range) & 96 (45 to 120$)$ & $91(5$ to 120$)$ & $0.08^{\dagger}$ \\
\hline \multicolumn{4}{|l|}{ Hips } \\
\hline 0 to 45 & 1 & 2 & $<0.0001^{\ddagger}$ \\
\hline 46 to 90 & 35 & 45 & \\
\hline 91 to 120 & 38 & 27 & \\
\hline Abduction $\left({ }^{\circ}\right)$ (range) & $32(15$ to 40$)$ & $28(0$ to 40$)$ & $0.002^{\dagger}$ \\
\hline \multicolumn{4}{|l|}{ Hips } \\
\hline$<20$ & 7 & 10 & $<0.0001^{\ddagger}$ \\
\hline 21 to 30 & 39 & 52 & \\
\hline 31 to 40 & 28 & 12 & \\
\hline \multicolumn{4}{|l|}{ Hip centre } \\
\hline Vertical distance from the teardrop line (range) & $24.4(9.1$ to 38.3$)$ & $25.9(13.3$ to 38.5$)$ & n.s. ${ }^{\S}$ \\
\hline Lateral distance from the vertical line ${ }^{*}$ (range) & $82.1(72.2$ to 96.1$)$ & $85.7(73.1$ to 100.4$)$ & n.s. ${ }^{\S}$ \\
\hline \multicolumn{4}{|l|}{ Loosening (\%) } \\
\hline \multicolumn{4}{|l|}{ Hips } \\
\hline Acetabular component & $4(5.4)$ & $4(5.4)$ & n.s. ${ }^{\S}$ \\
\hline Stem & $2(2.7)$ & $1(1.4)$ & n.s. ${ }^{\S}$ \\
\hline \multicolumn{4}{|l|}{ Revision (\%) } \\
\hline \multicolumn{4}{|l|}{ Hips } \\
\hline Acetabular component & 0 & $2(2.7)$ & n.s. ${ }^{\S}$ \\
\hline Stem & 0 & $1(1.4)$ & n.s. ${ }^{\S}$ \\
\hline \multicolumn{4}{|l|}{ Osteolysis (\%) } \\
\hline \multicolumn{4}{|l|}{ Hips } \\
\hline Acetabular component & $1(1.4)$ & $3(4.1)$ & n.s. \\
\hline Femoral & $20(27)$ & $57(77)$ & $<0.0001^{\dagger}$ \\
\hline Total & $20(27)$ & $59(79.7)$ & $<0.0001^{\dagger}$ \\
\hline Stress shielding (grade I/II, hips) & $22 / 2$ & $23 / 2$ & n.s. ${ }^{\S}$ \\
\hline \multicolumn{4}{|l|}{ Complications of the hip } \\
\hline Infection & 0 & 0 & n.s. ${ }^{\S}$ \\
\hline Dislocation & 0 & 0 & n.s. ${ }^{\S}$ \\
\hline Ceramic head breakage & 0 & 0 & n.s. ${ }^{\S}$ \\
\hline \multicolumn{4}{|l|}{ Complications of modular neck } \\
\hline Disassociation & 0 & - & \\
\hline Fracture & 0 & - & \\
\hline Notch formation & 0 & - & \\
\hline
\end{tabular}

leg length showed that these were equal in 68 of 74 hips $(92 \%)$ in the modular group and in 45 of 74 hips $(61 \%)$ in the non-modular group $(\mathrm{p}<0.001)$. There were no disassociations, fractures of the ceramic head, dislocations or infection in either group (Table III).

\section{Discussion}

Although this was a retrospective study with a small number of hips, the groups were well-matched for age, gender and Crowe's classification. The modular femoral neck system with the articulation of the modular alumina ceramic head and the gamma-sterilised conventional polyethylene liner in cementless THR provided favourable long-term results without severe complications at a minimum of 13 years' follow-up.

The total HHS and the range of abduction at the latest follow-up were significantly better in the modular group than those in the non-modular group. There was no significant difference in the range of movement as measured by the HHS, as abduction $>20^{\circ}$ is not recognised.

In the non-modular group, elevated liners were used in each case and the range of movement was decreased as 


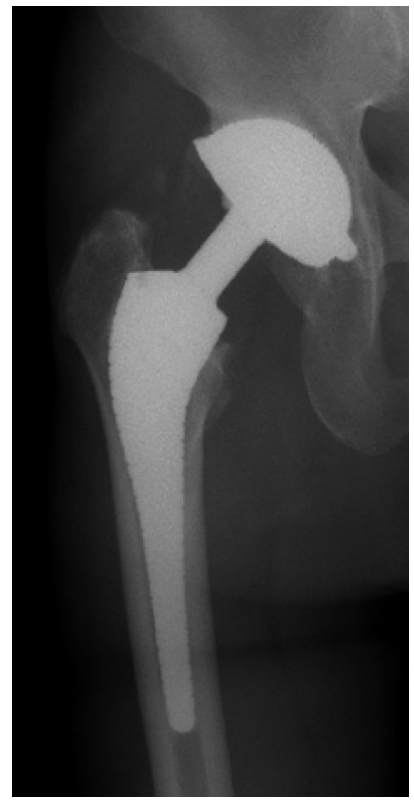

Fig. 3a

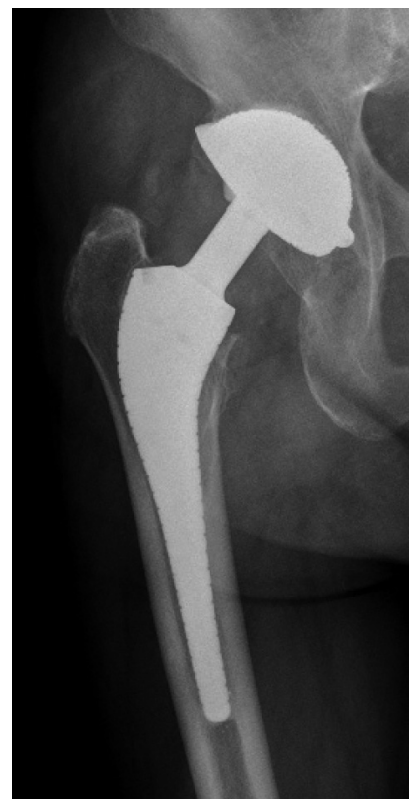

Fig. $3 b$

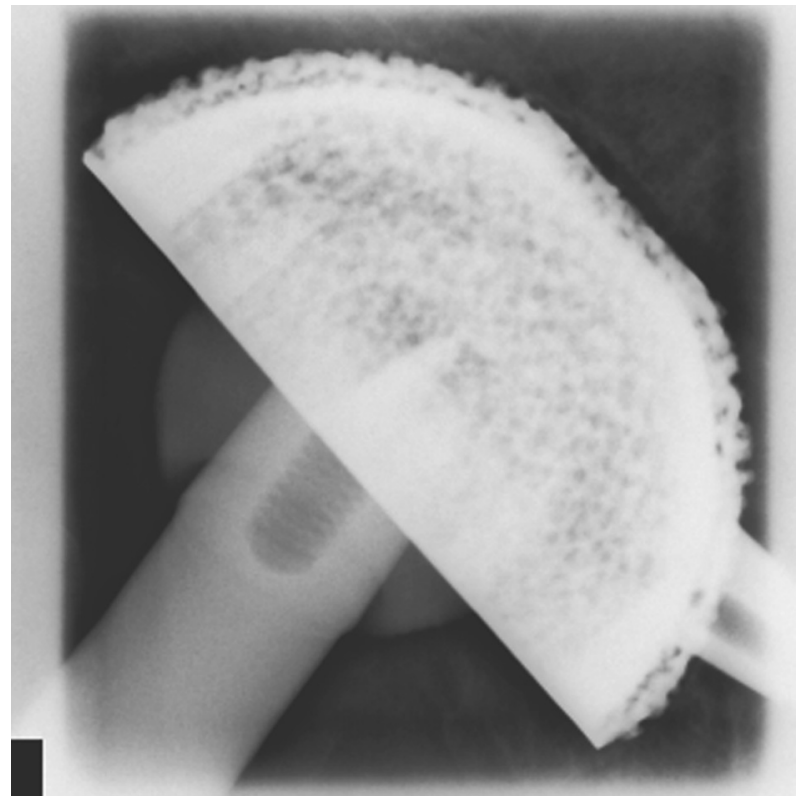

Fig. 3c

Immediate post-operative AP radiograph of a) modular replacement, b) the same prostheses after 15 years shows no osteolysis and c) radiological examination using high-voltage radiation ( $120 \mathrm{kVp}, 20 \mathrm{mAs})$ shows no migration of the hip centre.

Table IV. Osteolysis between the neutral liners and the $10^{\circ}$ elevated liners (n. s., not significant)

\begin{tabular}{|c|c|c|c|c|}
\hline \multirow[b]{2}{*}{ Osteolysis } & \multirow{2}{*}{$\begin{array}{l}\text { Neutral liners in the modular } \\
\text { group } \\
\mathbf{5 1} \text { hips (\%) }\end{array}$} & \multirow{2}{*}{$\frac{10^{\circ} \text { elevated liners in the modular group }}{23 \text { hips }(\%)}$} & $10^{\circ}$ elevated liners in the non-modular group & \multirow[b]{2}{*}{ p-value* } \\
\hline & & & 74 hips (\%) & \\
\hline \multicolumn{5}{|l|}{ Hips (\%) } \\
\hline Acetabular & 0 & $1(4.3)$ & $3(4.1)$ & n.s. ${ }^{\dagger}$ \\
\hline Femoral & $7(13.7)$ & $13(56.5)$ & $57(77)$ & $<0.0001^{*}$ \\
\hline Total & $7(13.7)$ & $13(56.5)$ & $59(79.7)$ & $<0.0001^{*}$ \\
\hline
\end{tabular}

* chi-squared test, A p-value of $<0.05$ was taken as statistically significant

$\dagger$ n. s., not signicant

expected. ${ }^{22}$ There was no disassociation between modular neck and stem. This may be due to the axial shape and length of the trunnion of the connection. One case report has shown disassociation of a different modular femoral neck from a well-fixed femoral component. ${ }^{6}$ The connection in this case was by a round-shaped taper with a tapered junction, which is ellipsoidal in shape in the axial plane, and carries a $16 \mathrm{~mm}$ long trunnion.

There were no fractures of the modular neck in this study, probably because of the high proportion of light women in each group.

We could not see whether fretting wear or corrosion had occurred, because there were no revisions in the modular group and because there is no non-invasive method of identifying fretting wear or corrosion in vivo. In a previous series with a ceramic-on-ceramic bearing and the same modular femoral neck system, two of 170 hips were revised and we found no severe corrosion macroscopically at the junction of the femoral neck and stem. ${ }^{23}$ In vitro studies have shown that the modular titanium neck-stem is resistant to corrosion in air, $\mathrm{FeCl}_{3}$ solution and physiological Ringer's solution. ${ }^{4}$ As far as fretting is concerned the ISO 7206/3 standard would suggest that the modular tapered joint would produce $0.6 \mathrm{mg} / \mathrm{year}$ of metal debris, whereas a normal stable prosthesis is likely to produce something less than $10 \mathrm{mg} / \mathrm{year}$ of metal debris. The production of a further $0.6 \mathrm{mg} / \mathrm{year}$ from the modular neck should not have any significant effect. ${ }^{5}$

We could not evaluate polyethylene wear directly using conventional plain radiographs. However, we used highvoltage radiation to investigate migration of the centre of the hip and polyethylene wear in cases of osteolysis. Migration was present in each case, suggesting that polyethylene wear could be related to femoral osteolysis, despite the fact that we could identify no differences in polyethylene wear between the two groups.

Osteolysis was greater with an elevated polyethylene liner and an alumina ceramic head. The modular femoral neck system with a modular alumina ceramic head and liner may give better long-term results, provided there is no 


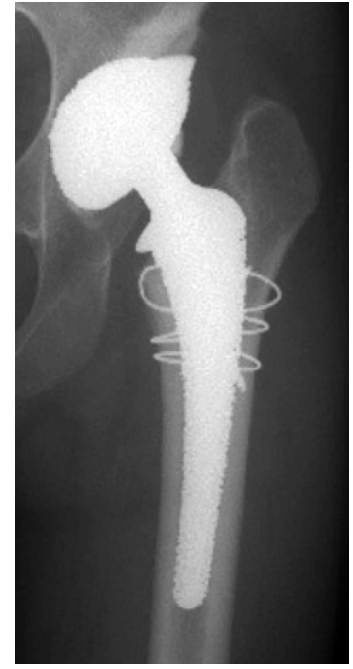

Fig. 4a

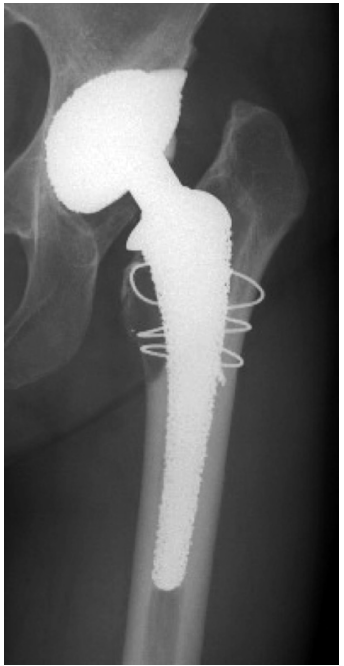

Fig. $4 \mathrm{~b}$

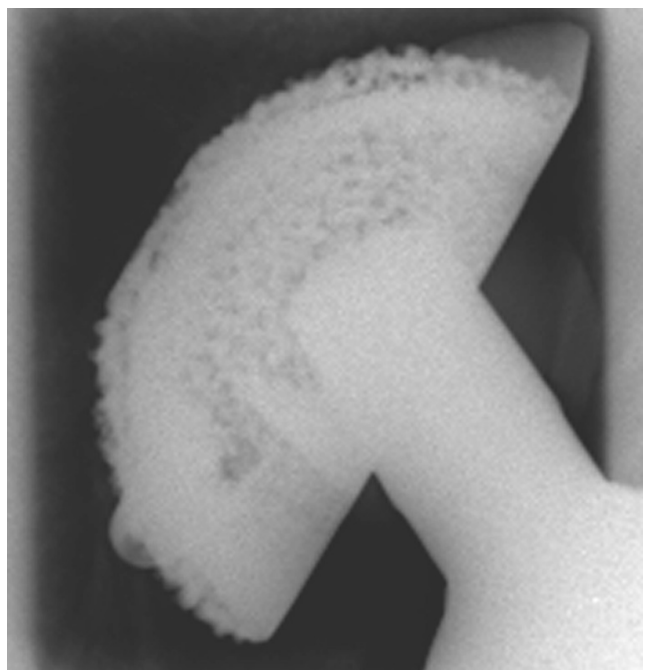

Fig. 4c

Immediate post-operative anteroposterior radiograph of a) non-modular replacement with wiring for an intra-operative fracture, a $10^{\circ}$ elevated liner was used, b) after nine years there is severe proximal femoral osteolysis and c) radiological examination using highvoltage radiation ( $120 \mathrm{kVp}, 20 \mathrm{mAs}$ ) shows that the hip centre has migrated proximally.

chipping or breakage of the ceramic articulation and titanium alloy. ${ }^{23}$

Although further, longer follow-up is desirable, we found no clinical problems related to the modular neck after a minimum of 13 years' follow-up. The modular femoral neck system reduces the need for an elevated liner with its tendency to greater osteolysis, and can improve the range of movement, and provide for adjustment of leg length.

We thank Dr S. Nishihara, Dr M. Aihara and Professor H. Yoshikawa for technical support.

No benefits in any form have been received or will be received from a commercial party related directly or indirectly to the subject of this article.

\section{References}

1. Sakai T, Sugano N, Nishii T, et al. Optimizing femoral anteversion and offset after total hip arthroplasty, using a modular femoral neck system: an experimental study. J Orthop Sci 2000;5:489-94.

2. Sariali E, Mouttet A, Pasquier G, Durante E, Catone Y. Accuracy of reconstruction of the hip using computerised three-dimensional pre-operative planning and a cementless modular neck. J Bone Joint Surg [Br] 2009;91-B:333-40.

3. Sakai T, Sugano N, Ohzono K, et al. Femoral anteversion, femoral offset, and abductor lever arm after total hip arthroplasty using a modular femoral neck system. J Orthop Sci 2002;7:62-7.

4. Viceconti M, Ruggeri O, Toni A, Giunti A. Design-related fretting wear in modular neck hip prosthesis. J Biomed Mater Res 1996;30:181-16.

5. Viceconti M, Baleani M, Squarzoni S, Toni A. Fretting wear in a modular neck hip prosthesis. J Biomed Mater Res 1997;35:207-16.

6. Sporer SM, DellaValle C, Jacobs J, Wimmer M. A case of disassociation of a modular femoral neck trunion after total hip arthroplasty. J Arthroplasty 2006;21:918-21.

7. McKellop HA, Sarmiento A, Brien W, Park SH. Interface corrosion of a modula head total hip prosthesis. J Arthroplasty 1992;7:291-4.

8. Star MJ, Colwell CW Jr, Donaldson WF 3rd, Walker RH. Dissociation of modular hip arthroplasty components after dislocation: a report of three cases at differing dissociation levels. Clin Orthop 1992;278:111-15.

9. Chu CM, Wang SJ, Lin LC. Dissociation of modular total hip arthroplasty at the femoral head-neck interface after loosening of the acetabular shell following hip dislocation. J Arthroplasty 2001;16:806-9.
10. Karaismailoglu TN, Tomak Y, Gulman B. Late detachment modular femoral component after primary total hip replacement. Arch Orthop Trauma Surg 2001;121:481-2.

11. Goldberg JR, Gilbert JL, Jacobs JJ, et al. A multicenter retrieval study of the taper interfaces of modular hip prostheses. Clin Orthop 2002;401:149-61

12. Crowe JF, Mani VJ, Ranawat CS. Total hip replacement in congenital dislocation and dysplasia of the hip. J Bone Joint Surg [Am] 1979;61-A:15-23.

13. Sakai T, Sugano N, Ohzono K, Lee SB, Nishii T. The custom femoral component is an effective option for congenital hip dysplsia. Clin Orthop 2006;451:146-53.

14. Sugano N, Saito S, Takaoka K, et al. Spongy metal Lübeck hip prostheses for osteoarthritis secondary to hip dysplasia: a 2-6-year follow-up study. J Arthroplasty 1994;9:253-62.

15. Matsui M, Nakata K, Masuhara K, et al. The Metal-Cancellous Cementless Lübeck total hip arthroplasty: five-to-nine year results. J Bone Joint Surg [Br] 1998;80B:404-10.

16. Harris WH. Traumatic arthritis of the hip after dislocation and acetabular fractures: treatment by mold arthroplasty: an end-result study using a new method of result evaluation. J Bone Joint Surg [Am] 1969;51-A:737-55.

17. Asayama I, Chamnongkich S, Simpson KJ, Kinsey TL, Mahoney OM. Reconstructed hip joint position and abductor muscle strength after total hip arthroplasty. $J$ Arthroplasty 2005;20:414-20.

18. Callaghan JJ, Dysart SH, Savory CG. The uncemented porous-coated anatomic total hip prosthesis: two-year results of a prospective consecutive series. J Bone Joint Surg [Am] 1988;70-A:337-46.

19. Ito H, Matsuno T, Minami A, Aoki Y. Intermediate-term results after hybrid total hip arthroplasty for the treatment of dysplastic hips. J Bone Joint Surg [Am] 2003;85A:1725-32

20. Woolson ST, Hartford JM, Sawyer A. Results of a method of leg-length equalization for patients undergoing primary total hip replacement. J Arthroplasty 1999;14:159-64.

21. Ranawat CS, Rao RR, Rodriguez JA, Bhende HS. Correction of limb-length inequality during total hip arthroplasty. J Arthroplasty 2001;16:715-20.

22. Krushell RJ, Burke DW, Harris WH. Elevated-rim acetabular components: effect on range of motion and stability in total hip arthroplasty. J Arthroplasty 1991;6(Suppl):53-8

23. Sugano N, Nishii T, Miki H, et al. Mid-term results of cementless total hip replacement using a ceramic-on-ceramic bearing with and without computer navigation. $J$ Bone Joint Surg [Br] 2007;89-B:455-60. 